CASTELLANOS-REDONDO Sonia, NEVADO-PEÑA Doming, LÓPEZ-RUIZ Víctor-Raúl, HUETE-ALCOCER Nuria

\title{
A STUDY BY GENDER IN HAPPINESS AT WORK IN SPANISH FINANCIAL SECTOR
}

In Happiness And Contemporary Society : Conference Proceedings Volume (Lviv, March, 20-21, 2021). Lviv: SPOLOM, 2021. P. 59-61. https://doi.org/10.31108/7.2021.10

ISBN 978-966-919-697-2 
https://doi.org/10.31108/7.2021.10

CASTELLANOS-REDONDO Sonia

Phd Student in Economics

University of Castilla-La Mancha (Albacete, Spain)

\author{
NEVADO-PEÑA Domingo \\ Professor in Accountancy \\ University of Castilla-La Mancha (Ciudad Real, Spain) \\ LÓPEZ-RUIZ Víctor-Raúl \\ Professor in Econometrics \\ University of Castilla-La Mancha (Albacete, Spain)
}

HUETE-ALCOCER Nuria

Assistant Professor in Econometrics

University of Castilla-La Mancha (Albacete, Spain)

\title{
A STUDY BY GENDER IN HAPPINESS AT WORK IN SPANISH FINANCIAL SECTOR
}

Using a survey of working-age Spanish citizens in 2020, we established a measure of organizational ethics based on the possible discrepancy between citizen's personal happiness and their happiness at work. The analysis focused on one of the essential economic sectors in the face of the pandemic, the financial sector. These workers demand organizational ethics with clear values in social responsibility and training, going beyond the achievement of a socially acceptable income. Other socio-demographic variables, such as gender, are of great interest for the analysis, being able to identify wage inequality and job satisfaction, which are more pronounced in the financial sector. Women are less happy at work, because of their job position and personal worth, thus being a key line to continue investigating in terms of corporate social responsibility and search for happiness of human capital.

KEYWORDS: happiness at work, gender, quality of life, ethics, pandemic.

\section{INTRODUCTION}

Happiness, understood as a state of well-being, has attracted the attention of many researchers from a range of disciplines in recent years. Certainly, the concept transcends merely having sufficient income (Castellanos et al., 2020). In the measurement and concept of happiness, Veenhoven (2005) and Diener and Seligman (2004) consider that happiness reveals the individual evaluation of the general aspects of life and conditions, and how much an individual likes life lived. Bearing in mind the amount of time we spend working over the course of our lives, it can clearly be seen that one of the areas that most influences our happiness is work. In other words, for people to be happy, they must have a good work environment in which to develop (Castellanos et al. 2020). While work and employment are drivers of happiness, happiness itself can also help to shape job market outcomes, productivity, and even firm performance (De Neve y Ward, 2017). The concept of happiness at work thus takes on even greater importance, since it is both a cause and an effect of people's well-being, going beyond job atisfaction.

The objective of this study is to analyse organizational ethics at work, understood as social responsibility towards the worker, with special attention paid to the financial sector and possible gender differences. We examine the relationship between the worker's vision of their happiness, and the organization's responsibility for making it possible. For this, we start from the organizational ethics, which can be measured 
through the difference between life and work satisfaction for the citizen. We study from the happiness model, the main dimensions of quality of life that justify it, and what are the gender differences in an essential sector in times of pandemic. For the analysis, we have the opinion of 933 Spanish citizens, through an online questionnaire developed by the Intangibles and Quality of Life Observatory in the summer of 2020.

\section{METHODOLOGY AND DATA}

The tabulation method chosen was with a 10-point Likert scale (1 being "not at all satisfied" to 10 "very satisfied") on the degree of satisfaction of citizens in some aspects of the quality of life in their place of residence and work, related to the different dimensions that affect the achievement of their happiness, according to different previous analyses by scholars (Nevado et al, 2019). Some questions related to COVID19 and its effect on quality of life were also included.

The data collection was carried out between July 2 and September 8, 2020, through an online questionnaire, distributed mostly by email and social networks, the sample obtained being 933 responses, which represents an estimation error. 3.2\% at a 95\% confidence level.

The distribution of responses according to the gender variable was $45 \%$ male for the financial sector (39\% for all sectors).

\section{RESULTS AND CONCLUSIONS}

Job satisfaction fosters happiness in the worker, which leads companies to prioritize strong ethical values and social responsibility. To measure citizens' happiness, we can directly ask respondents about their satisfaction with their life (LS), and also approach it indirectly by asking them about the dimensions of quality of life (residential place, economic situation and labor conditions). In the case of happiness at work, we will focus on the job satisfaction indicator $(\mathrm{HaW})$, but include the effects of proactivity towards training, the work environment, and the company's social responsibility, based on its response to the COVID-19 pandemic.

According to this happiness model, organizational ethics can be explained by the gap between both types of happiness, and in this way, the worker with a positive difference will be more productive, committed, and proactive (Castellanos et al., 2020).

The results of the analysis are collected in the Table, comparing the financial sector by gender versus the rest of the sectors, with the average value, standard error and coefficient of variation (CV) for each selected variable.

The Spanish financial sector, essential during the pandemic, shows lower values of organizational ethics (-1.37) than the rest of the sectors $(-0.74)$, because of a lower value of happiness at work (HaW) and higher in life satisfaction (LS). The study according to gender reveals even greater differences for the female, whose job satisfaction is only 6.46 (vs 7.67 male). For this group, organizational ethics is -1.89 , much lower than women in the rest of the sectors (-0.93), and with a lower CV. The differences are significant, we analyze what reasons or dimensions explain it.

The selected variables that explain the differences in the value of organizational ethics by gender, for the financial sector, are working conditions (economic, labor relations, culture/training). Received economic income ( 7.51 female vs 7.77 male), and the valuation and personal fulfillment of the workers are key. In addition, the female gender is more critical of the training activities of companies.

Lastly, the external factor of the pandemic (Covid19) has negatively affected the quality of life in a similar way, that is, there are no significant changes either by sector or by gender.

In summary, the salary gap and inequality in employment position by gender are relevant in the Spanish financial sector, causing serious deficiencies in social responsibility and organizational ethics.

From the Observatory of Intangibles and Quality of Life, we are researching on a model that relates the main dimensions of quality of life, measuring their importance, and establishing a dynamic and international comparison, by sector and by gender. 
Table: Values of main variables by sectors and gender

\begin{tabular}{|c|c|c|c|c|c|c|c|c|c|}
\hline & Happiness & Ethics & LS & Job & Safety & Economic & Labor & Culture & Covid19 \\
\hline & & LS-HaW & & $\mathrm{HaW}$ & & & relations & training & $(-)$ \\
\hline Sector & Values & & & & & & & & \\
\hline \multirow{3}{*}{$\begin{array}{l}\text { Financial } \\
\text { (Total) }\end{array}$} & Mean & -1.37 & 8.37 & 7.00 & 7.97 & 7.63 & 8.25 & 6.79 & 6.99 \\
\hline & Std error & 2.22 & 1.45 & 2.35 & 1.60 & 1.64 & 1.24 & 2.33 & 2.33 \\
\hline & $\mathrm{CV}$ & 1.62 & 0.17 & 0.34 & 0.20 & 0.21 & 0.15 & 0.34 & 0.33 \\
\hline \multirow[t]{3}{*}{ Male } & Mean & -0.73 & 8.40 & 7.67 & 7.87 & 7.77 & 8.47 & 7.30 & 7.03 \\
\hline & Std error & 2.21 & 1.52 & 2.44 & 2.11 & 1.94 & 1.12 & 2.70 & 2.52 \\
\hline & $\mathrm{CV}$ & 3.01 & 0.18 & 0.32 & 0.27 & 0.25 & 0.13 & 0.37 & 0.36 \\
\hline \multirow[t]{3}{*}{ Female } & Mean & -1.89 & 8.35 & 6.46 & 8.05 & 7.51 & 8.08 & 6.38 & 6.95 \\
\hline & Std error & 2.10 & 1.40 & 2.13 & 1.01 & 1.33 & 1.30 & 1.88 & 2.17 \\
\hline & $\mathrm{CV}$ & 1.11 & 0.17 & 0.33 & 0.13 & 0.18 & 0.16 & 0.29 & 0.31 \\
\hline \multirow{3}{*}{$\begin{array}{l}\text { Non- } \\
\text { Financial } \\
\text { (Total) }\end{array}$} & Mean & -0.74 & 8.10 & 7.36 & 8.04 & 7.16 & 8.34 & 6.50 & 6.88 \\
\hline & Std error & 2.25 & 1.74 & 2.23 & 1.53 & 2.20 & 1.52 & 2.49 & 2.35 \\
\hline & $\mathrm{CV}$ & 3.04 & 0.22 & 0.30 & 0.19 & 0.31 & 0.18 & 0.38 & 0.34 \\
\hline \multirow[t]{3}{*}{ Male } & Mean & $-0,43$ & 8,01 & 7,58 & 8,00 & 7,35 & 8,25 & 6,54 & 6,85 \\
\hline & Std error & 1,74 & 1,78 & 2,03 & 1,65 & 2,05 & 1,43 & 2,40 & 2,38 \\
\hline & $\mathrm{CV}$ & 4,05 & 0,22 & 0,27 & 0,21 & 0,28 & 0,17 & 0,37 & 0,35 \\
\hline \multirow[t]{3}{*}{ Female } & Mean & $-0,93$ & 8,15 & 7,22 & 8,07 & 7,05 & 8,39 & 6,48 & 6,90 \\
\hline & Std error & 2,50 & 1,72 & 2,33 & 1,46 & 2,28 & 1,56 & 2,54 & 2,34 \\
\hline & $\mathrm{CV}$ & 2,69 & 0,21 & 0,32 & 0,18 & 0,32 & 0,19 & 0,39 & 0,34 \\
\hline
\end{tabular}

Source: OICV, University of Castilla La Mancha (Spain).

\section{REFERENCES}

1. Castellanos-Redondo, S., Nevado-Peña, D., \& Yañez-Araque, B. (2020). Ethics and Happiness at Work in the Spanish Financial Sector. Sustainability, 12(21), 9268.

2. De Neve, J. E., \& Ward, G. (2017). Happiness at work. Saïd Business School WP, 7.

3. Diener, E. \& Seligman, M.E. (2004). Beyond money toward an economy of wellbeing. Psychological Science in the Public Interest, 5(1), 1-31.

4. Nevado-Peña, D., López-Ruiz, V. R., \& Alfaro-Navarro, J. L. (2019). Improving quality of life perception with ICT use and technological capacity in Europe. Technological Forecasting and Social Change, 148, 119734.

5. OICV (2020). Felicidad y Calidad de Vida de los españoles. Informe 1. Semestre II. Available in:

6. https://blog.uclm.es/victorlopez/files/2020/10/informe-felicidad-22-10-2020.pdf

7. Veenhoven, R. (2005). Inequality of happiness in nations. Journal of Happiness Studies, 6(4), 351-355. 